Adverse effects caused by beta blockers, and number of patients per beta blocker and per adverse effect

\begin{tabular}{|c|c|c|c|c|c|c|c|c|c|}
\hline \multirow[b]{2}{*}{ Beta blocker } & \multirow[b]{2}{*}{$\begin{array}{l}\text { Average daily } \\
\text { dose }(\mathrm{mg})\end{array}$} & \multicolumn{7}{|c|}{ No of patients with: } & \multirow[b]{2}{*}{$\begin{array}{c}\text { No of } \\
\text { patients per } \\
\text { beta blocker }\end{array}$} \\
\hline & & $\begin{array}{l}\text { Shoulder } \\
\text { joint affected }\end{array}$ & $\begin{array}{l}\text { Polyarthritic } \\
\text { symptoms }\end{array}$ & $\begin{array}{c}\text { Blocked } \\
\text { nose }\end{array}$ & $\begin{array}{l}\text { Impaired } \\
\text { peripheral } \\
\text { circulation }\end{array}$ & $\begin{array}{c}\text { Eye } \\
\text { symptoms }\end{array}$ & $\begin{array}{l}\text { Bronchial } \\
\text { obstruction }\end{array}$ & $\begin{array}{c}\text { Dry } \\
\text { mouth }\end{array}$ & \\
\hline $\begin{array}{l}\text { Metoprolol } \\
\text { Propranolol } \\
\text { Pindolol } \\
\text { Acebutolol } \\
\text { Atenolol } \\
\text { Alprenolol } \\
\text { Timolol }\end{array}$ & $\begin{array}{r}100 \\
75 \\
5 \\
240 \\
50 \\
600 \\
30\end{array}$ & $\begin{array}{r}13 \\
3 \\
5 \\
3 \\
2 \\
1 \\
1\end{array}$ & $\begin{array}{l}4 \\
1 \\
3 \\
2 \\
1 \\
1\end{array}$ & $\begin{array}{l}1 \\
2 \\
2 \\
2 \\
1\end{array}$ & $\begin{array}{l}7 \\
2 \\
2 \\
2 \\
1\end{array}$ & $\begin{array}{l}2 \\
1 \\
1 \\
1 \\
1\end{array}$ & 1 & $\begin{array}{r}10 \\
1 \\
1 \\
1 \\
1\end{array}$ & $\begin{array}{r}15 \\
4 \\
10 \\
6 \\
2 \\
1 \\
1\end{array}$ \\
\hline $\begin{array}{l}\text { No of patients per } \\
\text { adverse effect }\end{array}$ & & 15 & 5 & 2 & 7 & 3 & 1 & 10 & \\
\hline
\end{tabular}

The rapid resolution of the symptoms when the drug was stopped supports this hypothesis.

Why so few cases of arthropathy related to beta blockade have been reported over the years is difficult to explain. No similar cases have been reported to the National Centre for Monitoring Adverse Drug Reactions of the Medical Board of Finland. The main manufacturers of metoprolol have received several reports of joint complaints occurring in patients taking the drug, but in none was a clear cause and effect relation established. It may be that joint complaints are so common in the age group commonly treated with the drugs that the part these drugs play in causing joint problems escapes attention. It may also be that the phenomenon occurs more often with certain beta blockers; in our experience metoprolol seemed most likely to induce joint complaints.

${ }^{1}$ Fraser DM, Irvine NA. Joint effusion and practolol. Lancet $1976 ; \mathrm{i}: 89$.

${ }^{2}$ Machtey I. Polyarthritis following propranolol. Arthritis Rheum $1981 ; 24$ : $568-9$.

${ }^{3}$ Kaplan R, Robinson CA, Scavulli JF, Vaughan JH. Propranolol and the treatment of rheumatoid arthritis. Arthritis Rheum 1980;23:253-5.

4 Famey JP, Appelboom T. Leucocyte receptors to classical pharmacological mediators (modification by beta receptors of leucocyte adherence to glass). European fournal of Rheumatology and Inflammation 1979;2: 108-14

(Accepted 21 fune 1983)

Internal Medicine Unit, Pieksämäki Regional Hospital, 76100

Pieksämäki 10, Finland

JAAKKO SAVOLA, MD, physician in charge

\section{Seasonal trends in childhood asthma in south east England}

Studies in other countries ${ }^{1-3}$ have shown pronounced seasonal variation in admissions for acute asthma, but there are few published data from Britain. Examination of the asthma admission data for our hospital (Royal Alexandra Hospital for Sick Children, Brighton) and for the South East Thames region showed clear seasonal variation with a notable increase in admissions in the autumn.

\section{Present study and results}

Hospital admission data for asthma (code number ICD 493) were obtained through Hospital Activity Analysis for this hospital and the South East Thames region. Information was requested by age group (0-4, 5-14 years) and month and year of admission. Data for the Royal Alexandra Hospital were cross checked against the ward admission book. Full information was obtained for the 10 years 1971-80 for our hospital and the five years 1975-9 for the South East Thames region.

The figure shows the cumulated monthly admission data for the Royal Alexandra Hospital for all ages over the 10 years and the cumulated monthly admission data for the South East Thames region for the age groups 0-4 and 5-14 years. In all three groups the admission rate was low during January to April and rose in early summer. Admissions consistently fell in August and were followed by a peak in September and October. Subdividing the data for our hospital into 0-4 and 5-14 year age groups disclosed an identical pattern.

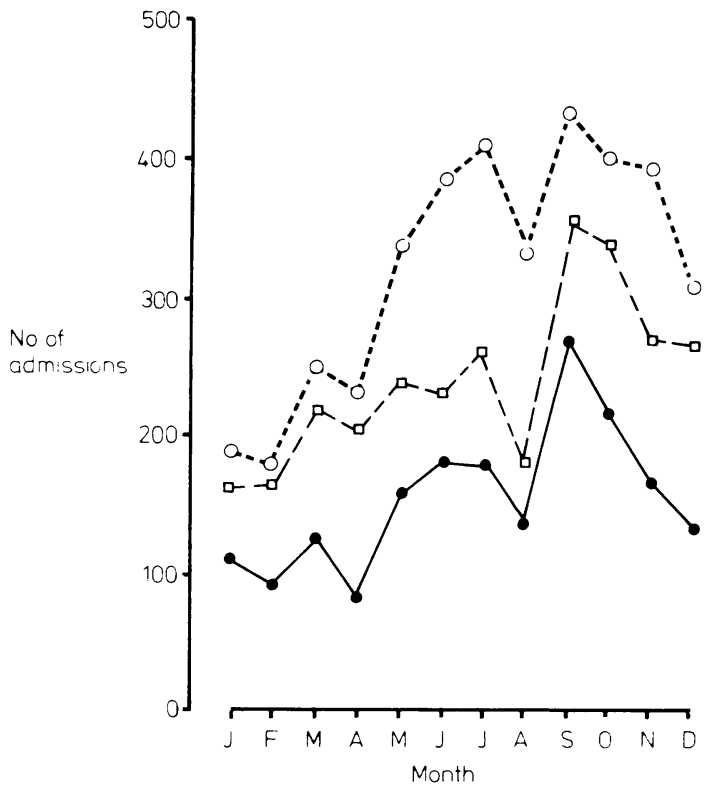

Cumulated monthly hospital admissions* of children with asthma. - Royal Alexandra Hospital for Sick Children, Brighton (0-14 years), 1971-80. $]-\square$ South East Thames region (0-4 years), 1975-9. $\bigcirc-\bigcirc$ South East Thames region (5-14 years), 1975-9.

*In fact, Hospital Activity Analysis records asthma admissions as asthma discharges.

\section{Comment}

Inaccuracies in Hospital Activity Analysis data are most likely to arise due to diagnostic transfer. There is reluctance to use the word asthma, especially in younger children, in whom the terms wheezy bronchitis or asthmatic bronchitis have been used. These and other synonyms are usually coded as bronchitis unqualified (ICD 490). Acute bronchiolitis and acute bronchitis are coded together under ICD 466. Criteria for the diagnosis of asthma have changed little since 1970 at the Royal Alexandra Hospital and the number of admissions diagnosed as bronchitis unqualified is extremely small. Similarly the admission rate for acute bronchiolitis has not altered over the years and is mainly restricted to the months December to April.

As well as pronounced seasonal variation, examination of data for our hospital and the South East Thames region showed a steadily increasing yearly admission rate. Total admissions for asthma at the Royal Alexandra Hospital in 1971 were 75 , increasing to 284 in 1980. The reasons for this are complex and the phenomenon has been noted before. ${ }^{4}$

The early summer peak was expected and may be related to inhaled pollens. We were surprised to find a consistent fall in admissions in August both locally and regionally. Environmental or social factors may be responsible and these need further investigation. The peak in admissions in September and October concurs with parents' views that their asthmatic children are more wheezy in the autumn and agrees with studies from other countries. Environmental trigger factors such as climatic changes, fungal and pollen spores, air pollution, viruses, and house dust mite may be important aetiologically.

It seems unlikely that childhood asthma in south east England 
behaves differently from that in other parts of Britain. Seasonal trends have important implications in the planning of therapeutic trials and may help to identify environmental trigger factors in childhood asthma. A further study of national data is warranted.

We thank the Hospital Activity Analysis and statistical staff of the South East Thames region for their help.

1 Booth S, DeGroot IDO, Markush R, Horton RSM. Detection of asthma epidemics in seven cities. Arch Environ Health 1965;10:152.

2 Derrick EH. Asthma and the Brisbane climate. Aust NZ $\mathcal{F}$ Med 1972;3 : 235.

${ }^{3}$ Tromp SW. Influence of weather and climate on asthma and bronchitis. Review of Allergy 1968;22:1027.

${ }^{4}$ Anderson HR. Increase in hospitalisation for childhood asthma. Arch Dis Child 1978;53:295.

(Accepted 17 June 1983)

Royal Alexandra Hospital for Sick Children, Brighton BN1 3JN ALEX KHOT, $\mathrm{MB}, \mathrm{DCH}$, research associate

NIGEL EVANS, MRCP, DCH, consultant paediatrician

WARREN LENNEY, MD, MRCP, consultant paediatrician

Correspondence to: $\mathrm{Dr} W$ Lenney.

\section{Non-steroidal anti-inflammatory drugs and oral lichenoid reactions}

The aetiology of lichen planus is unknown. Stress, autoimmunity, underlying mesodermal disease, and infective agents have all been suggested as possible causes but have not gained wide support. Many drugs can provoke eruptions that clinically and histologically are similar to or even identical with lichen planus. Such lichenoid reactions may be caused by, for example, gold salts, methyldopa, quinine, and beta-blockers ${ }^{1}$ and may affect mucosal or cutaneous sites, either alone or together.

We describe a probable association between treatment with non-steroidal anti-inflammatory drugs and oral lichenoid reaction.

\section{Case report}

A 64 year old man presented to the oral medicine clinic, Birmingham Dental Hospital, with a five week history of soreness, white areas, and ulceration of the buccal mucosa. There was no history of skin, ocular, or genital lesions. He had been taking indomethacin for rheumatoid arthritis for 10 months. No other drug had been prescribed for 18 months.

Intraorally there were bilateral shallow erosions of the buccal mucosa surrounded by a network of lacy white striae typical of erosive lichen planus. There was no clinical evidence of arthropathy associated oral ulceration, including Behçet's syndrome, ulcerative colitis, or Reiter's syndrome.

Biopsy of the buccal mucosa showed atrophic parakeratinised oral epithelium with liquefaction degeneration of the basal cell layer. There was a band-like infiltrate of lymphocytes and histiocytes in the lamina propria immediately beneath the epithelium. These features are typical of oral lichen planus. Blood count and biochemical profile were normal.

Local treatment, initially with chlorhexidine and later with prednisolone mouthwash, provided no relief; indeed, the erosions became more widespread. Ibuprofen was substituted for indomethacin with minimal oral improvement. All medication was withdrawn and a short course of systemic steroids instituted. Within two weeks the oral ulceration had resolved. Because of increasing arthritic pain indomethacin suppositories were prescribed. Excellent relief of arthritic pain was produced but oral erosions recurred. The erosions did not respond to prednisolone mouthwashes but when the rectal indomethacin was discontinued they healed within 10 days. Fenclofenac and diflunisal were later prescribed, but these also produced oral erosion, which healed rapidly on withdrawal of the drugs. Soluble aspirin and aspirin-paracetamol combinations were prescribed, and the oral erosions resolved, with fading of the lichenoid striae. This improvement was maintained for about six months, but because of increasing arthritic pain the patient was prescribed flurbiprofen. Oral erosions returned and the lichenoid striae became very pronounced once again. These persisted essentially unchanged while the patient continued to take flurbiprofen.

\section{Comment}

These observations strongly suggest that indomethacin provoked the initial oral lichenoid eruption. The rapid recurrence of oral erosions on rechallenge with both indomethacin and other nonsteroidal anti-inflammatory agents and their equally rapid resolution on drug withdrawal indicate a causal relation between non-steroidal anti-inflammatory agents in general and oral lichenoid reactions. These drugs are known to be associated with non-specific oral ulceration but there is no previous documentation implicating them in oral lichenoid reactions.

The Committee on the Safety of Medicines has received a few reports of lichenoid reactions associated with non-steroidal antiinflammatory drugs (West Midlands Adverse Drug Reaction Monitoring Centre, personal communication).

On reviewing the records of 75 patients with oral lichen planus attending Birmingham Dental School's oral medicine clinic it was apparent that 20 of these were receiving non-steroidal anti-inflammatory drugs at the time of presentation. Clearly such an association in many of these patients will be coincidental, reflecting similar population groups susceptible to lichen planus and arthritic disorders. Within the group, however, there were seven patients whose oral lichenoid erosions resolved when the drugs were withdrawn. Two of them were rechallenged with the offending drug, producing a recurrence. In four other patients ibuprofen, fenbufen, sulindac, and benoxaprofen may have provoked oral lichenoid reactions.

In our patient there was a delay between beginning medication and the onset of oral eruptions. Holt and Navaratnam described such a phenomenon in methyldopa induced lichenoid eruptions. ${ }^{2}$ On withdrawal and rechallenge with this drug, however, the lichenoid eruptions resolved and recurred more rapidly. The eruptions provoked by non-steroidal anti-inflammatory drugs appear to behave similarly, recurrence of lichenoid reaction occurring within six days after rechallenge with fenbufen in one patient.

A controlled study is now under way to elucidate further this possible drug reaction.

Thanks are due to Professor H D Edmondson, Professor R M Browne, and $\mathrm{Mr} \mathrm{J}$ W Frame, whose patients formed the basis of this report. We also acknowledge the help of Dr L Beeley and the West Midlands Adverse Drug Reaction Monitoring Centre.

${ }^{1}$ Duxbury AJ. Systemic pharmacotherapy. In: Jones JH, Mason DK, eds. Oral manifestations of systemic disease. London: WB Saunders Co Ltd, 1980:454-89.

${ }^{2}$ Holt PJA, Navaratnam A. Lichenoid eruption due to methyldopa. $\mathrm{Br}$ Med F 1974;iii :234.

(Accepted 17 fune 1983)

The Dental School, St Chad's Queensway, Birmingham B4 6NN J HAMBURGER, BDS, MSC, department of oral surgery and oral medicine A J C POTTS, BDS, MRCPATH, department of oral pathology

Correspondence to: $\mathrm{Mr} \mathrm{J}$ Hamburger.

\section{Double blind cross over trial of ipratropium and placebo in chronic rhinorrhoea}

Watery rhinorrhoea in patients with perennial rhinitis responds poorly to treatment with topical beclamethasone diproprionate and disodium cromoglycate. ${ }^{1}$ Systemic antihistamines are effective in some cases but are associated with an unacceptable level of side effects. Ipratropium bromide, a topically active anticholinergic drug, inhibits rhinorrhoea induced by metacholine ${ }^{2}$ and produces symptomatic improvement in selected patients with perennial rhinorrhoea and abnormal reactivity to metacholine. ${ }^{3} \mathrm{We}$ assessed its use in unselected patients presenting with chronic watery rhinorrhoea as their main symptom.

\section{Patients, methods, and results}

Twenty men and women aged $18-78$, mean 40 were referred consecutively to our clinic with chronic watery rhinorrhoea. All consented to the trial, completed a questionnaire on the nature and duration of symptoms, and underwent full otolaryngological examination, sinus radiology, and skin prick testing to common allergens. Rhinorrhoea had been present for one to 20 (mean five) years and lasted for a mean of $11 \cdot 1$ hours a day. Eight 